\title{
Fracture of Nitinol under Quasistatic and Dynamic Loading
}

\author{
FENGCHUN JIANG and KENNETH S. VECCHIO
}

\begin{abstract}
Owing to the potential application of Nitinol as an advanced structural material, it is essential to thoroughly understand the deformation and fracture behavior of Nitinol under various loading conditions. The present study explores the fracture behavior of Nitinol under quasistatic and dynamic loading, with emphasis on the fracture toughness and fracture mechanism of Nitinol. To this end, the precracked bend sample was employed to perform dynamic fracture testing using a modified (pulse-shaped) Hopkinson-pressure-bar-loaded fracture-testing system. The dynamic fracture initiation toughness was measured under stress-state equilibrium conditions at a loading rate of $\sim 10^{6} \mathrm{MPa} \sqrt{\mathrm{m}} / \mathrm{s}$. To further investigate the fracture mechanism, additional dynamic fracture tests were performed using double-crack, four-point bend samples. The experimental results indicate that the dynamic fracture toughness of Nitinol is higher than it is under quasistatic loading, and that the loading rate influences the fracture mechanisms of Nitinol. The interplay between the dynamic strength of Nitinol and the activation stress for stress-induced martensite (SIM) transformation plays an important role in the fracture behavior of Nitinol.
\end{abstract}

DOI: $10.1007 / \mathrm{s} 11661-007-9349-5$

(C) The Minerals, Metals \& Materials Society and ASM International 2007

\section{INTRODUCTION}

NitinOL is a thermoelastic alloy with a composition of approximately 50 at. pet $\mathrm{Ni}$ and 50 at. pet $\mathrm{Ti}$, capable of two successive thermal martensite phase transformations on cooling from its higher-temperature austenite phase. Nitinol has excellent physical and mechanical properties of interest, such as shape-memory effect, biocompatibility, sueperelasticity, and thermal fatigue and corrosion resistance. These characteristics enable Nitinol to have wide utilization as a functional material in medical implants, as well as in electrical, aerospace, and mechanical engineering applications. ${ }^{[1-3]}$ Recently, studies have shown that Nitinol and its composites have potential applications in engineering practice, as structural materials. ${ }^{[3-8]}$ Superelastic Nitinol undergoes a large recoverable strain during loading, due to stress-induced martensitic transformation, and generates a large hysteretic loop upon unloading, which enables Nitinol to absorb significant energy during superelastic deformation. This large strain-energy absorption capability has recently been considered for improving the impact tolerance of composite structures and vibration damping devices, in which the components can be integrated into critical parts of structures that may need protection from impact loads ${ }^{[9]}$ and used to protect buildings and bridges against earthquake vibration damage. ${ }^{[3]}$ As a consequence, the study of the

FENGCHUN JIANG, Project Scientist, and KENNETH S. VECCHIO, Professor, are with the Department of NanoEngineering, University of California, San Diego, La Jolla, CA 92093-0411. Contact e-mail: kvecchio@ucsd.edu

This article is based on a presentation given in the symposium "Dynamic Behavior of Materials," which occurred February 26March 1, 2007, during the TMS Annual Meeting in Orlando, FL, under the auspices of the TMS Structural Materials Division and the TMS/ASM Mechanical Behavior of Materials Committee.

Article published online October 30, 2007 deformation and fracture behavior of Nitinol and its composites under various loading conditions becomes critical for the large-scale utilization of Nitinol. The mechanical response of Nitinol has been extensively studied experimentally and theoretically, at both quasistatic $^{[10-17]}$ and high strain rates. ${ }^{[18-23]}$ However, the utilization and the potential application of Nitinol in long-life components as a structural material requires a thorough understanding of the dominant deformation and fracture mechanisms of Nitinol under different loading conditions. ${ }^{[2]}$ Recently, the mechanical response and fracture behavior of Nitinol and its composites under cyclic loading have been studied ${ }^{[25-29]}$ and the effect of stress-induced martensite (SIM) transformation on deformation and fracture behavior of Nitinol $^{[31-42]}$ has received more attention. It is recognized that SIM formation in the crack-tip zone will significantly influence the fracture properties as well as the deformation and fracture mechanisms of Nitinol. Wang et al. ${ }^{[32]}$ using finite-element analysis (FEA), indicated that the amount of SIM and the extension of the transformed region are dependent upon the crack-tip radius and crack length. Some recent numerical analysis results ${ }^{[34-36]}$ revealed that SIM forms at very low loads in a precracked compact tension sample, and that the plastic deformation, crack initiation, and crack propagation all occur within a SIM zone. The SIM transformation improves the fracture toughness of Nitinol in both mode I and mixed I/II loadings. ${ }^{[33,34,37,38]}$ However, the FEA results of Yan et al.$^{[39]}$ indicated that the martensite phase transformation in Nitinol, with its volumetric contraction, tends to reduce its fracture resistance and increase its brittle behavior. In experimental observations of the fracture characteristics of Nitinol, Lopez et al. ${ }^{[30,31]}$ revealed that the formation of numerous fine martensite plates or "apparent" new grains at the crack tip results in an increase in the fracture toughness of Nitinol. Gall et al. ${ }^{[24]}$ found that 
at least two different failure mechanisms exist in aged single-crystal and polycrystalline Nitinol. The nucleation, growth and coalescence of voids from $\mathrm{Ti}_{3} \mathrm{Ni}_{4}$ precipitates dominate the fracture behavior in aged polycrystalline Nitinol. More recently, Chen et al. ${ }^{[40]}$ demonstrated that a quasicleavage mode prevails in the fracture process of Nitinol, and SIM transformation plays an important role in improving the toughness of Nitinol.

To our knowledge, there has been very limited work done ${ }^{[36,41,42]}$ concerning the quasistatic fracture toughness of Nitinol. However, in these articles, the fracture mechanism of Nitinol was not systematically investigated using precracked samples. Furthermore, dynamic fracture toughness data and investigation into damage evolutional and fracture mechanisms in Nitinol under high-rate loading are still lacking. In this work, to more completely understand the fracture behavior of Nitinol, fracture toughness tests were performed under quasistatic and dynamic loadings, using single-edge, precracked samples in four-point bend fracture. The fracture mechanisms were also investigated through scanning electron microscopy (SEM) observations of the sample fracture surfaces. Furthermore, the microdamage (void and crack) evolution and crack-propagation behavior were investigated using double-notched bend fracture samples, in which one notch initiates a crack that fractures the sample, while the other notch initiates a crack that arrests within the unbroken ligament, for subsequent observation of fracture path and mechanism.

\section{EXPERIMENTAL PROCEDURE}

\section{A. Experimental Details}

Fracture tests were performed at room temperature using four-point bend samples under both quasistatic and dynamic loading conditions. The quasistatic testing was carried out on a servohydraulic machine at an extension rate of $0.5 \mathrm{~mm} / \mathrm{min}$, and the critical fracture load was determined in terms of ASTM Standard E399. The dynamic fracture testing was performed on a modified two-bar/bend Hopkinson pressure system with momentum trap technique. The incident $\left(\varepsilon_{I}\right)$ and the reflected $\left(\varepsilon_{R}\right)$ strains are measured by the strain gage mounted at the midpoint of the incident bar, while the transmitted $\left(\varepsilon_{T}\right)$ strain is measured by the strain gage attached at the midpoint of the transmission bar. At the conditions of dynamic stress-state equilibrium, the dynamic load, $P(t)$, and the sample deflection, $\delta(t)$, can be calculated, using the one-dimensional stress wave theory, as ${ }^{[43]}$

$$
\begin{gathered}
P(t)=E A_{o} \varepsilon_{T}(t) \\
\delta(t)=2 C_{o} \int_{o}^{t} \varepsilon_{R}(t) d t
\end{gathered}
$$

where $E, C_{o}$, and $A_{o}$ are the elastic modulus, longitudinal sound speed, and cross-section area, respectively, of the Hopkinson bars. Pulse-shaping was employed to ensure that the cracked sample fractured within the firstincident pulse period under stress-state equilibrium conditions; detailed experimental analysis of the pulseshaping for this bend fracture test method can be found elsewhere $^{[44]}$ In the present work, a small strain gage with gage dimensions of $0.79 \mathrm{~mm} \times 1.57 \mathrm{~mm}$ is attached near the crack tip, to detect the fracture time, ${ }^{[4]}$ determined by the abrupt drop in strain associated with crack extension. The stress-intensity factor in the fourpoint bend is computed by ${ }^{[45]}$

$$
\begin{aligned}
K= & \frac{3 P L}{B W^{2}} \sqrt{\pi a}\left[1.122-1.121 a / W+3.740(a / W)^{2}\right. \\
& \left.+3.873(a / W)^{3}-19.05(a / W)^{4}+22.55(a / W)^{5}\right]
\end{aligned}
$$

where $L=\left(S_{1}-S_{2}\right) / 2$, with $S_{1}$ and $S_{2}$, the external (26-mm) and internal (13-mm) spans, for both quasistatic and dynamic fracture tests (Figure 1(a)). Equation [3] has been employed elsewhere to calculate the stressintensity factor in quasistatic four-point bend tests. ${ }^{[46-48]}$ As demonstrated previously, ${ }^{[4]}$ stress-state equilibrium is achieved in the current Hopkinson-bar fracture test throughout most of the loading period; ${ }^{[44]} \mathrm{Eq}$. [3] is therefore applicable for calculating the dynamic stressintensity factor for measuring fracture toughness. It is worth pointing out that four-point bend testing is perhaps the best method for measuring the fracture toughness of Nitinol for one important reason: in the four-point bend fracture, only the sample's configuration (the dimensions and crack length) and applied load are necessary for calculating the stress-intensity factor; no material properties, such as the elastic modulus and Poisson's ratio, are needed. However, these material parameters must be known in a three-point bend fracture test (ASTM E399), and are assumed to be constant throughout the test. This is a poor assumption in the deformation and fracture of Nitinol, in which phase transformations, such as SIM, take place in the

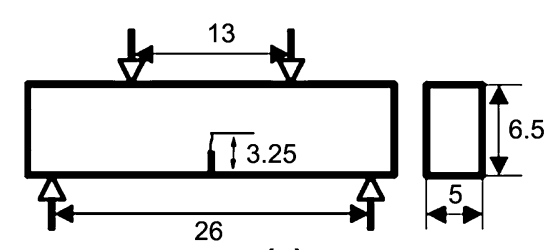

(a)

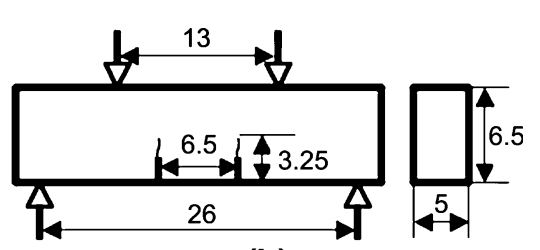

(b)

Fig. 1-Four-point bend sample configurations employed in fracture tests: $(a)$ single-cracked and (b) double-cracked (all dimensions are in millimeters). 
crack-tip plastic zone. At this point, the sample consists of the parent austenite phase and SIM, and the mechanical properties of these two phases are different.

Double-notch (crack) bending tests were employed here to further study the fracture mechanism of Nitinol. The sample has two cracks of identical length (Figure 1(b)); complete failure occurs only at one crack, and the remaining crack with a certain crack extension is unloaded immediately, when the other crack starts unstable propagation. As a result, the information with respect to the fracture process, such as damage initiation, evolution, and other fracture characteristics, is arrested in the nonfractured side of the sample for further analysis. This double-notched sample technique has been widely employed in the study of the fracture mechanism. ${ }^{[46-57]}$ In dynamic-loading fracture testing, in which it is difficult to arrest the fracture process by unloading, the double-notched sample is necessary for studying damage evolution at different deformation and fracture stages. The dynamic fracture toughness data can be collected from the completely fractured portion, and the fracture path characteristics can be observed from the sectioning of the unbroken, but cracked, portion.

\section{B. Material and Sample}

Nitinol (SE-508, 55.6 Ni wt pet Ti) used in this study was purchased from Nitinol Devices and Components (NDC, Fremont, CA) in the form of 0.5 -in. (12.7-mm) stock; the chemical composition and transformation temperatures of this Nitinol alloy are given elsewhere. ${ }^{[23]}$ Bend samples (single- and double-crack) with dimensions of $5 \mathrm{~mm}$ (thickness) $\times 6.5 \mathrm{~mm}$ (width) $\times 40 \mathrm{~mm}$ (length) were employed in both quasistatic and dynamic fracture tests, as shown in Figure 1. All samples were machined with their length parallel to the bar length, and the crack perpendicular to the bar length. The samples were fatigue precracked to a crack length/width ratio, $a / W \sim 0.5$, consistent with ASTM E399. To eliminate the effect of the SIM introduced by cyclic load during precracking, a small fatigue load was employed, and the stress-intensity factor applied to the sample was maintained at $\sim 5 \mathrm{MPa} \sqrt{\mathrm{m}}$ throughout the precracking step.

\section{Fracture Morphology Observation}

A PHILIPS* XL20 SEM was employed to examine

*PHILIPS is a trademark of Philips Electronic Instruments Corp., Mahwah, NJ.

fracture-surface micromorphology, and optical microscopy was used to investigate the damage evolution in the vicinity of the crack tip and to measure the crack extension in the double-cracked bend samples.

\section{FRACTURE TOUGHNESS OF NITINOL}

As pointed out elsewhere, ${ }^{[44]}$ stress-state equilibrium is critical in the current Hopkinson-bar-loaded fracture

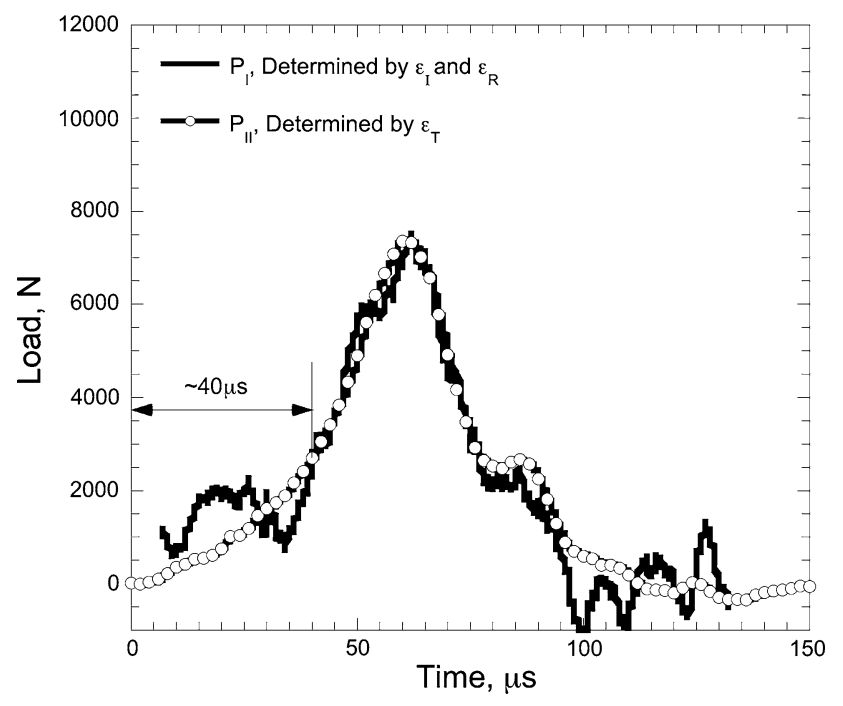

Fig. 2-Comparison between loads $P_{I}$ and $P_{I I}$. Here, $P_{I}$ is the load applied on the uncracked side of the sample, which is determined by the incident and reflected pulses. $P_{I I}$ is the load applied on the cracked side of the sample, determined by the transmitted pulse. The detailed calculation for $P_{I}$ and $P_{I I}$ can be seen in Ref. 44 .

test. Experimental results ${ }^{[44]}$ already demonstrated that stress-state equilibrium was achieved in the precracked four-point bend samples. For the sake of brevity, in this study, only the comparison between the loads $\left(P_{I}\right.$ and $\left.P_{I I}\right)$ applied on the two loading sides of the sample, as given in Figure 2, is used to show the stress-state equilibrium attained in the sample. Here, the load applied on the uncracked side of the bend sample $\left(P_{I}\right)$ and precracked $\left(P_{I I}\right)$ sides of the bend sample were determined by the incident and reflected pulses, and single transmitted pulse, respectively. ${ }^{[4]}$ As can be seen in Figure 2, over most of the loading period, the load variations $\left(P_{I}\right.$ and $\left.P_{I I}\right)$ as a function of time are in good agreement. This agreement indicates that the stress-state equilibrium has been achieved after $\sim 40 \mu \mathrm{s}$. The crackinitiation times (fracture time) detected by a small strain gage mounted near the crack tip is between $\sim 60$ and $70 \mu$ s (Table I), indicating that all dynamic fracture events, such as crack initiation and propagation, occur under stress-state equilibrium conditions. Therefore, the critical dynamic fracture parameters (load and deflection) can be determined by the one-dimensional stress theory (Eqs. [1] and [2]) and the dynamic fracture toughness, $K_{I d}$, can be also calculated by a quasistatic fracture mechanics approach (Eq. [3]).

Figure 3 shows a typical dynamic load vs deflection response for this configuration; the quasistatic response is also plotted for comparison. It can be seen in Figure 3 that both the load and the deflection increase with the increasing loading rate. The peak load and total deflection under dynamic loading conditions are more than twice the amplitude of the quasistatic response. Nitinol displays an increasing fracture toughness with an increasing loading rate. Apart from the influence of strain rate on flow stress affecting the high impact resistance of Nitinol, the reverse phase transformation (SIM $\rightarrow$ austenite (A)) occurring in the crack-tip zone 
Table I. Dynamic-Fracture-Initiation Toughness Experimental Results

\begin{tabular}{lcccc}
\hline Sample & $a_{o} / W$ & $t_{f}(\mu \mathrm{s})$ & $K_{I d}(\mathrm{MPa} \sqrt{\mathrm{m}})$ & $\left(\dot{K}_{I d} \mathrm{MPa} \sqrt{\mathrm{m}} / \mathrm{s}\right)$ \\
\hline 1 & 0.515 & 68.1 & 54.2 & $0.80 \times 10^{6}$ \\
2 & 0.500 & 66.1 & 57.4 & $0.87 \times 10^{6}$ \\
3 & 0.491 & 61.5 & 62.3 & $1.01 \times 10^{6}$ \\
4 & 0.507 & 64.9 & 59.4 & $0.92 \times 10^{6}$ \\
5 & 0.538 & 57.9 & 57.8 & $1.00 \times 10^{6}$ \\
6 & 0.507 & 67.5 & 61.2 & $0.91 \times 10^{6}$ \\
Average & 0.510 & 64.3 & 58.7 & $0.92 \times 10^{6}$ \\
\hline
\end{tabular}

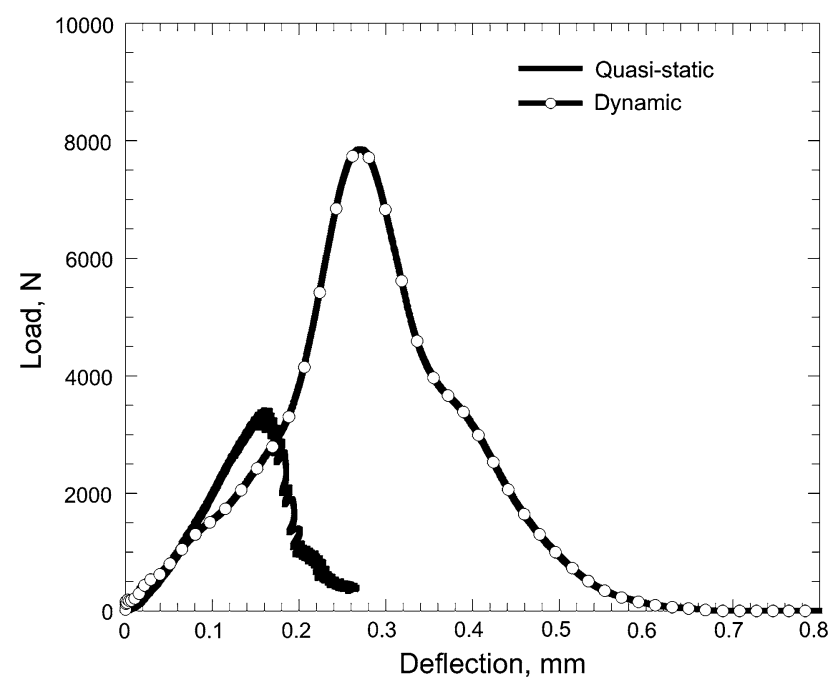

Fig. 3-Typical load-deflection response under quasistatic and dynamic loading conditions. The dynamic load and deflection were determined by Eqs. [1] and [2] at stress-state equilibrium conditions.

may also have an important effect. ${ }^{[22]}$ Since the material of the crack-tip zone undergoes high-rate deformation in an adiabatic state under dynamic loading, a significant localized temperature rise occurs. For example, it has been reported ${ }^{[58]}$ that the maximum temperature rise in the crack tip is up to $200{ }^{\circ} \mathrm{C}$ for steel. The temperature rise near the shear bands has also been shown by infrared (IR) and coating techniques to be quite high (several hundreds of degrees Celsius) under dynamic loading conditions. ${ }^{[59]}$ In this study, the crack-tip local temperature could be higher than the austenite transformation temperature, and the reverse transformation $(\mathrm{SIM} \rightarrow \mathrm{A})$ may occur before unloading. Unlike typical metal alloys, in which a higher temperature results in a decrease in strength, in Nitinol, the higher temperature in the crack-tip zone facilitates the SIM transforming back to austenite. Nitinol, therefore, shows high deformation resistance in a certain range of the elevated temperatures, ${ }^{[22]}$ since the austenite stiffness and strength are superior to those of martensite. ${ }^{[32]}$ From the viewpoint of energy, high impact resistance combined with larger deformation enables Nitinol to absorb more energy (plastic deformation work) during dynamic deformation and fracture processes, implying Nitinol has high fracture toughness under dynamic loading.
The average quasistatic fracture toughness, $K_{I c}$, is $\sim 39.0 \mathrm{MPa} \sqrt{\mathrm{m}}$, but does not satisfy plane-strain conditions, according to ASTM validity criteria. Quasistatic fracture toughness measured by the current four-point bend test is in very good agreement with the results reported in References 36 and 41, which are $\sim 39.4 \mathrm{MPa} \sqrt{\mathrm{m}}$, as determined by a precracked CT sample, ${ }^{[36]}$ and $\sim 39.2 \pm 2.8 \mathrm{MPa} \sqrt{\mathrm{m}}$, as determined by a single-edge notched tensile sample. ${ }^{[41]}$ However, these fracture-toughness values are higher than that given by Reference 42, in which the fracture toughness of a thinwalled superelastic Nitinol tube was determined using a compact tension (CT) sample at human body temperature, $37^{\circ} \mathrm{C}$. The dynamic-fracture-initiation toughness for six representative samples measured in our present work is summarized in Table I. Other fracture parameters (crack-initiation time and loading rate computed by $\dot{K}_{I}=K_{I d} / t_{f}$ ) are also listed in Table I. The average dynamic fracture initiation toughness of Nitinol was measured for the first time using our Hopkinson-barloaded four-point bend fracture test. The $\mathrm{K}_{I d}$ is $\sim 58.7 \mathrm{MPa} \sqrt{\mathrm{m}}$, at an average stress-intensity loading rate of approximately $9.2 \times 10^{5} \mathrm{MPa} \sqrt{\mathrm{m}} / \mathrm{s}$. The present experimental results indicate that the dynamic-fracture toughness of Nitinol is markedly greater than that obtained at quasistatic conditions. Considering these superior dynamic properties in both fracture toughness and impact resistance, Nitinol can be considered for utilization in some critical components in structural engineering that are subjected to high-rate impact loadings.

\section{FRACTOGRAPHY ANALYSIS}

It should be recognized that the material in the crack tip is fully austenitic before testing, and can transform to SIM during loading. When the sample unloads, some of the SIM recovers back to the parent austenite phase, while other portions are unrecoverable. Both austenite and residual SIM are present on the fractured surfaces. Therefore, the fracture surface morphology observed post-test may not accurately reflect the phases present during the fracture process. Nevertheless, some useful information on the deformation and fracture of SIM, as well as on the crack path, can be ascertained.

Figure 4 shows some typical fracture features obtained from the quasistatic fractured samples. To make appropriate comparisons between samples, images were recorded from the midthickness of the fractured sample, where a plane-strain stress-state dominates the fracture process. ${ }^{[0]}$ Figure 4(a) shows the steady-state fracture surface created by the quasistatic bend test, located just beyond the fatigue precrack region. Figure 4(b) shows the transition region (indicated by the dotted line) between the fatigue precracked region (lower half) and the steady-state fracture region (upper half). Figure 4(c) shows the fatigue precrack fracture surface, and Figure 4(d) shows the final fracture region at the end of the fracture surface. As can be seen from Figure 4, the quasistatic fracture samples show cleavage fracture characteristics within the steady-state fracture region, 

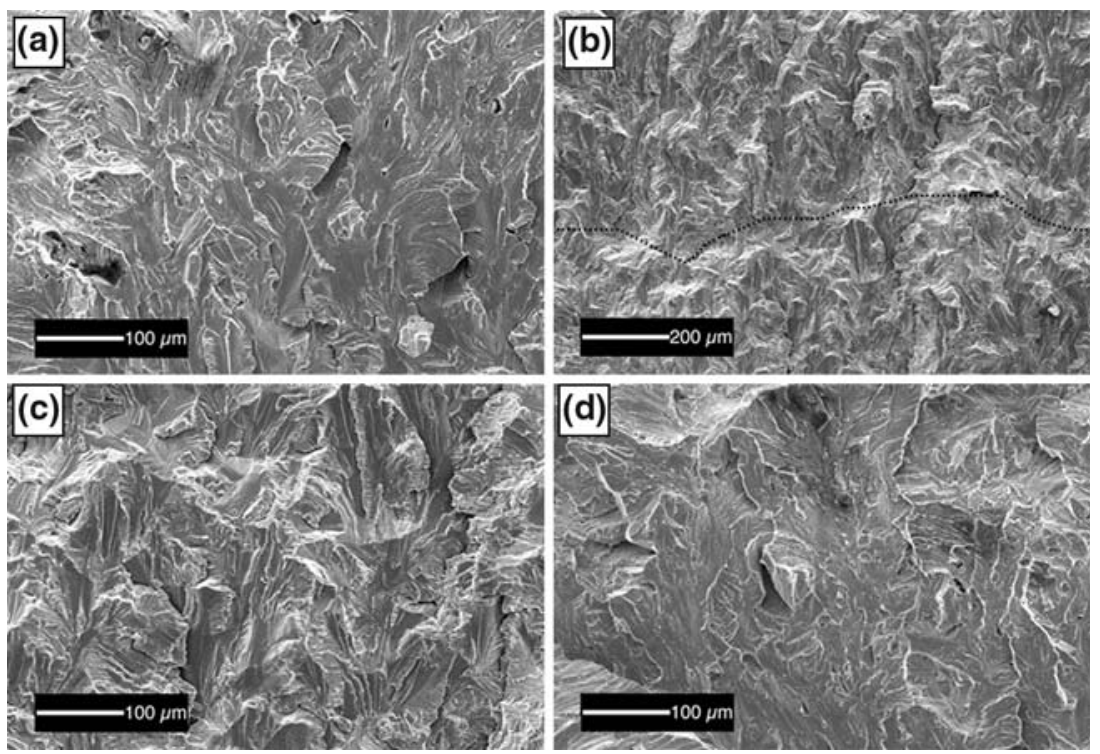

Fig. 4-SEM micrographs of quasistatic fracture features: (a) cleavage fracture in the steady-state fracture region just beyond the fatigue precrack transition region, (b) transition between the fatigue precrack region and steady-state fracture region (dotted line denotes boundary), $(c)$ fatigue precrack region morphology showing rougher features compared to steady-state fracture, and $(d)$ cleavage fracture in the final stages of failure.

and this mode is prevalent throughout the fracture process. For example, cleavage features, such as a feathery cleavage pattern (Figures $4(\mathrm{a})$ and (d)), are found throughout the fracture surface, whereas little or no ductile, dimplelike fracture could be found, which indicates that little plastic deformation occurred in the quasistatic fracture process. Therefore, the overall quasistatic fracture surface is quite smooth, compared to the case of dynamic loading (which will be discussed next), which correlates well with the lower fracture resistance and fracture toughness under quasistatic loading.

Figure 5 shows some typical fracture features obtained from the dynamic fractured samples. Figure 5(a) shows the steady-state fracture surface created by the dynamic bend test, located just beyond the fatigue precrack region. Figure 5(b) shows the transition region (indicated by the dotted line) between the fatigue precracked region (lower half) and the steady-state fracture region (upper half). The transition in this
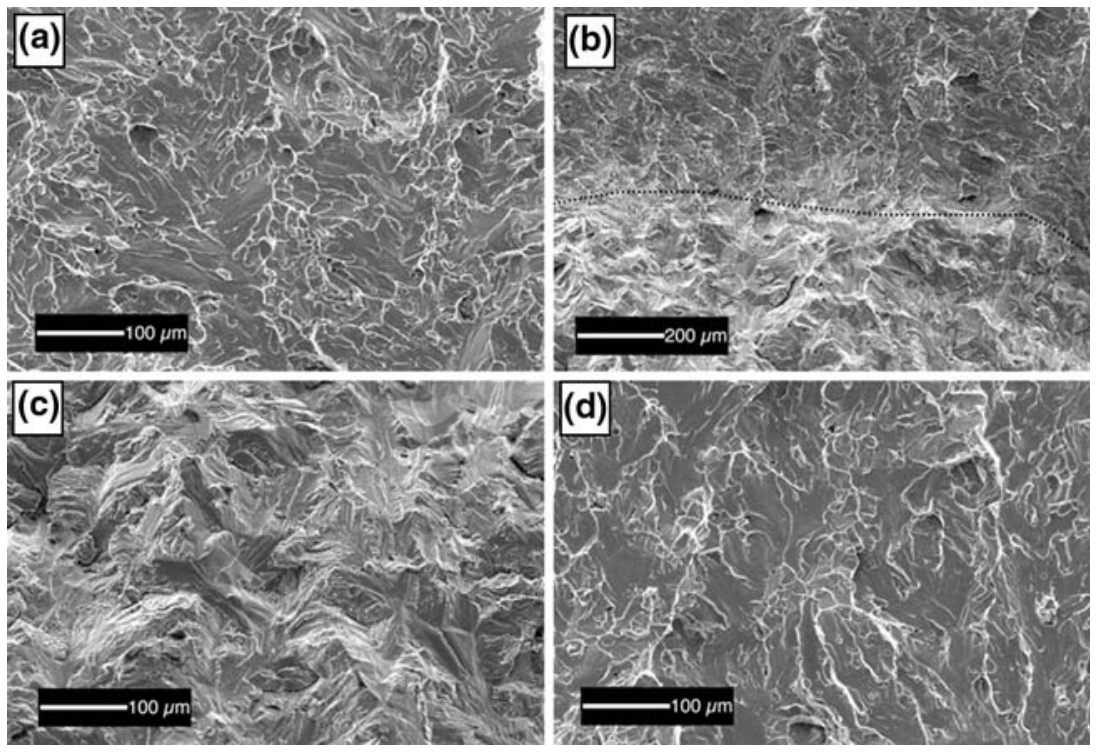

Fig. 5-SEM micrographs of dynamic fracture features: $(a)$ quasicleavage fracture in the steady-state fracture region just beyond the fatigue precrack transition region, showing numerous microvoids and ductile tearing; $(b)$ transition between the fatigue precrack region and steady-state fracture region (dotted line denotes boundary); $(c)$ fatigue precrack region morphology showing rougher features compared to steady-state fracture; and $(d)$ quasicleavage fracture in the final stages of failure, still showing evidence of microvoids and ductile tearing. 
dynamic test sample is much more evident, as compared to the transition in the quasistatic test sample. Figure 5(c) shows the fatigue precrack fracture surface, and Figure 5(d) shows the final fracture region at the end of the fracture surface. It is quite evident that the cleavage facets are largely intermixed with dimple microvoid type fracture (Figures 5(a) and (d)), and a larger number of tear ridges are present. The area fraction of the dimpled regions is relatively large and is present across the fracture surface of every dynamicallytested sample. As can be seen from the fracture surface, plastic deformation evidence is visible as numerous small-sized dimples that developed from microvoids. The existence of numerous dimples indicates that a relatively larger amount of plastic deformation takes place during the dynamic fracture process. Furthermore, the overall fracture surface shows a relatively higher roughness, as compared to the quasistatic fractured surface. Clearly, the ductile failure mode dominates the fracture process of Nitinol under dynamic loading. All these fractographic characteristics suggest that the fracture resistance of Nitinol is enhanced under dynamic loading conditions; the dynamic fracture of Nitinol tends toward a ductile failure mode that involves void nucleation, growth, and coalescence processes. The mechanism responsible for the transition to a more ductile fracture mode under dynamic loading will be discussed later.

\section{MICRODAMAGE EVOLUTION AND CRACK PROPAGATION}

The partially-cracked, double-notched bend sample was sectioned by a low-speed diamond blade and then cold-mounted in epoxy for further polishing; the polished samples were etched by a solution of $\mathrm{HF}$ and $\mathrm{HNO}_{3}$. A detailed sample-preparation technique can be found elsewhere. ${ }^{[52]}$ To analyze crack-propagation behavior using partially-cracked samples, the crack extension needs to be estimated. Here, the crack length was measured from the polished side of the sample using optical microscopy, and the extent of the crack advance was determined from a comparison of the crack lengths before and after loading. It is recognized that the crack extension in the midthickness of the bend sample is slightly greater than that measured from the side surface.

Figure 6 shows the difference in damage (microcrack) evolution and crack-propagation behavior between quasistatic and dynamic loadings. As can be seen from Figure 6(a), evidence of residual SIM is still visible in the dynamically-loaded sample. The residual SIM plates observed around the cracks indicate that the material around the crack tip has undergone extensive martensite phase transformation during fracture under dynamic loading. To ensure that these residual SIM plates form as a result of the bending load only, the sample surface was polished several times carefully with low pressure; it was found that the distribution, location, and morphology of the SIM did not change at each observation. This indicates that the SIM plates observed in the polished surface indeed formed during the fracture process, and that this was not a polishing artifact. Furthermore, as can be seen in Figure 6(a), a microcrack with a length of $\sim 25 \mu \mathrm{m}$ is found in front of the main moving crack. This small crack forms due to microvoid development (growth) at the inclusion site (a small inclusion is visible in the SEM observations) ahead of the crack and propagates toward the moving crack tip. The main crack grows by connecting similar pre-existing

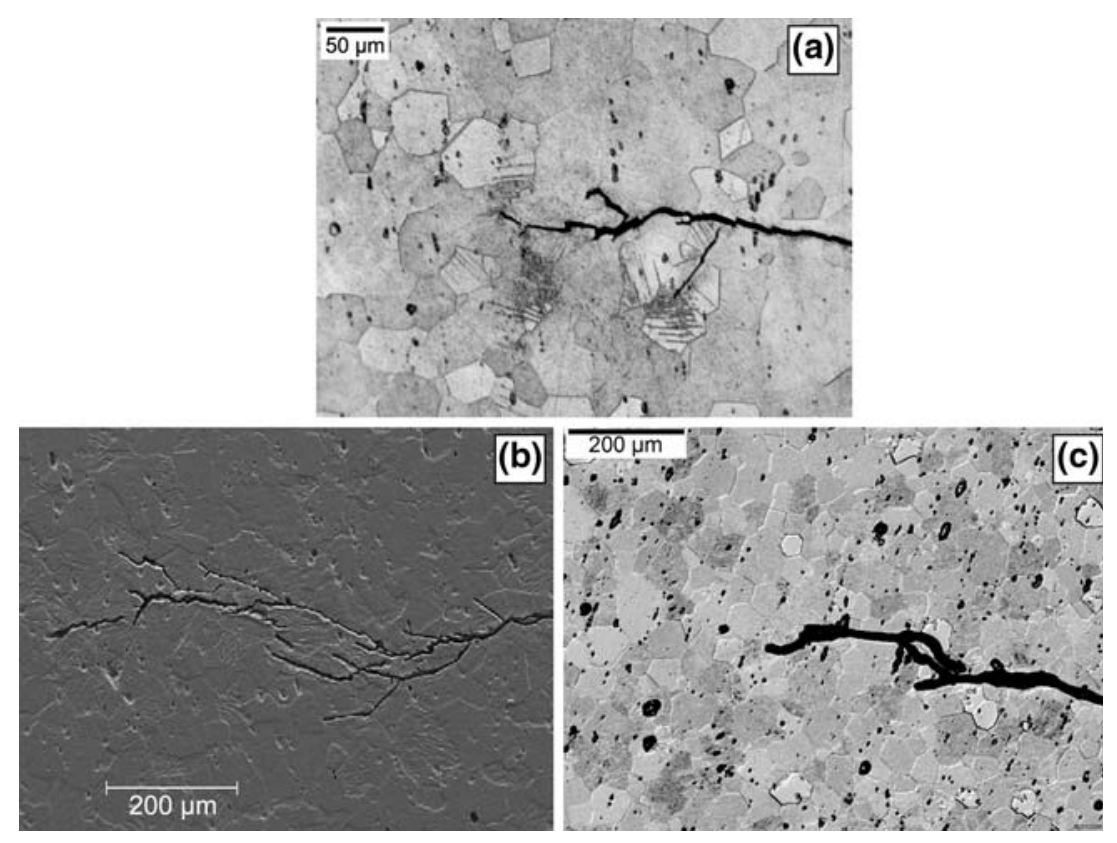

Fig. 6-Difference in damage evolution around the crack and crack-propagation path: $(a)$ optical micrograph of residual SIM around dynamic cracks, (b) SEM micrograph of dynamic crack branching, and (c) optical micrograph showing no residual SIM around quasistatic crack. The crack propagates from the right to left; the crack extensions are $\sim 700$ (a) and $\sim 800 \mu$ m (c) at two loading rates, respectively. 
microcracks. As a result, curved and branched cracks form (Figure 6(b)) due to the random distribution of the microcracks; these are dependent upon the distribution of inclusions and the crack-tip stress field within the fully-transformed SIM zone. Figure 6(c) shows the propagating-crack characteristic under quasistatic loading. Compared to the dynamic case, no obvious evidence of microcrack coalescence was found within the microdamage evolution region. Although the running crack tends to branch or bifurcate during the propagation process, the few branching cracks do not grow extensively, compared to those observed in the dynamic loading case. Perhaps most important, no residual SIM plates are evident in the crack-tip zone.

As pointed out previously in this article, the temperature rise due to the adiabatic heating effect under dynamic loading is beneficial to the reverse phase transformation from SIM back to austenite. Since under quasistatic loading there is no significant temperature rise, it would be reasonable to expect that more SIM would remain in the crack-tip zone of these samples, if it had formed during loading. However, more residual SIM and associated microcracks were found in the dynamic fracture samples. This observation implies that more SIM formed in the crack-tip zone during dynamic loading, and the SIM transformation promotes the formation of microcracks and their coalescence.

Figure 7(a) shows the stress-strain response of this Nitinol alloy, in both tension and compression, under both quasistatic and dynamic loading conditions. ${ }^{[23]}$ The material shows strong strain-rate sensitivity and a large degree of stress-state asymmetry, with the compressive strength significantly higher than the tensile strength. The bend-fracture samples tested in this current study experience a combination of tension and compression, but in both stress states, the dynamic response requires significant higher stress levels, as compared to the quasistatic response. Therefore, the strain-rate sensitivity clearly plays a significant role in increasing the measured fracture toughness under dynamic loading. However, the higher flow stress of Nitinol under dynamic loading does not appear to result in lower ductility, as is typically observed in metals, which contributes to a lowering of the overall toughness under dynamic loading conditions.

Figure 7(b) depicts schematically the flow stress of Nitinol as a function of temperature, under both dynamic and quasistatic loading conditions derived from previous work. ${ }^{[23]}$ Cross-plotted in Figure 7(b) is a schematic representation of the martensite transformation stress as a function of temperature. For the case of the roomtemperature fracture toughness testing of this Nitinol alloy, it is shown that the flow stress of Nitinol under quasistatic loading is lower than the martensite transformation stress, at the same temperature. This allows for the bulk of the specimen ahead of the crack-tip region, which is austenite, to deform by slip or fracture under quasistatic fracture testing, in preference to deformation by the SIM. The triaxiality of stress in the crack-tip region may also play a role in limiting the transformation to SIM. However, at the same test temperature, the dynamic flow stress of Nitinol is likely well above the martensite transformation stress; this situation is indicated by the open circle in Figure 7(b), located between the two slanted flow-stress lines. Since the stress ahead of the crack tip is above the critical stress required to initiate the SIM transformation, this region can begin transforming to martensite prior to reaching the flow-stress level of the parent phase, under dynamic loading conditions.

The fact that the fracture mechanism under dynamic loading (Figures 5(a) and (d)) is distinctly different than that under quasistatic loading (Figures 4(a) and (d)), with all other test parameters constant, suggests that either: (1) the phase present in the dynamically-loaded sample is, in fact, different from that present in the quasistatic sample, at the point that fracture begins to propagate, or (2) the mechanical behavior of the austenite phase present at room temperature is strongly influenced by the loading rate, such that it becomes significantly stronger and more ductile under dynamic loading. While it is common for metals to behave more strongly under dynamic loading, it is somewhat unusual

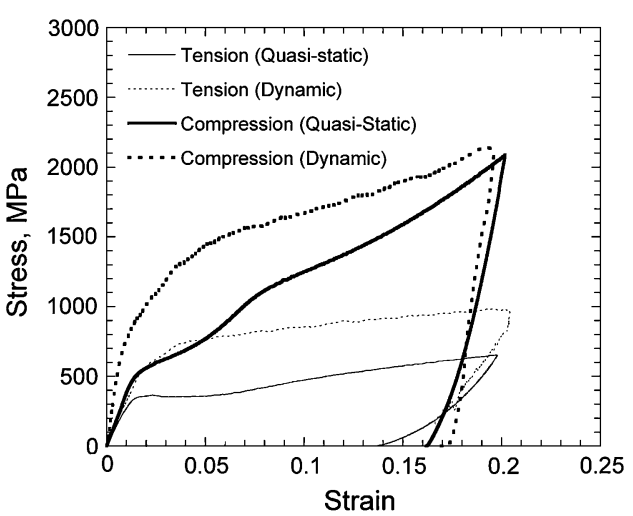

(a)

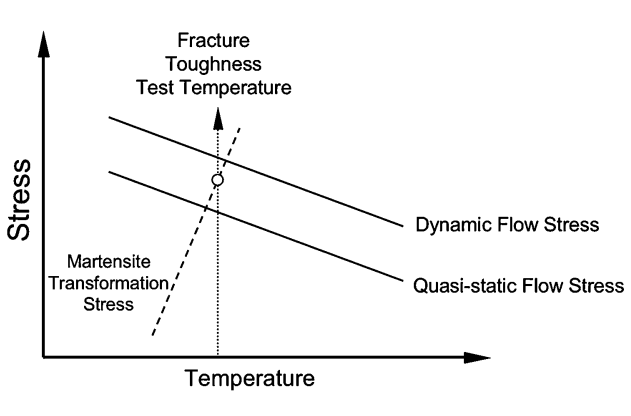

(b)

Fig. 7-(a) Plot of stress-strain response of Nitinol in both tension and compression under both quasistatic and dynamic loading rates, showing both strain-rate sensitivity and stress-state asymmetry of the responses and $(b)$ schematic representation of flow stress in Nitinol as a function of temperature at two different loading rates. Cross-plotted is a representation of the martensite transformation stress as a function of temperature. The circle represents a stress level/temperature combination that would facilitate SIM under dynamic loading prior to slip occurring in the austenite phase. 
for metals to become more ductile under these conditions, without a new deformation mechanism operating.

Further evidence for the transformation to martensite under dynamic fracture but not necessarily under quasistatic fracture, is given by the results in Figure 6, which show the presence of remnant martensite plates in the dynamic fracture sample, but not in the quasistatic fracture sample.

Additional experimental observation with respect to the microdamage evolution indicates that, regardless of high and low loading rates, the visible microdamage (microvoids or cracks) is initiated at inclusions. Energy dispersive $\mathrm{X}$-ray microanalysis identified that these inclusions are $\mathrm{Ti}_{2} \mathrm{Ni}$ and $\mathrm{Ti}_{3} \mathrm{Ni}_{2}$ types. Due to the high stress concentration at the inclusions, the stress level may exceed the critical stress required for martensite transformation under both loading conditions. The austenite surrounding these inclusions may first transform to martensite via a SIM transformation. However, these inclusions themselves do not undergo SIM transformation, but act as nucleation sites for both SIM transformation and microdamage (cracks and voids). As a result, the microdamage originates within the regions of SIM transformation and enlarges during its plastic deformation. Therefore, the current results demonstrate experimentally that the SIM transformation promotes the nucleation, growth, and coalescence of microvoids in the fully-transformed SIM crack-tip zone, leading to a highly ductile dynamic fracture behavior. These results, therefore, strongly support the previous conclusions derived from numerical analysis, ${ }^{[33,34,37,38]}$ that the SIM transformation can enhance the fracture resistance and fracture toughness of Nitinol.

\section{CONCLUSIONS}

1. The fracture toughness of Nitinol, determined by the Hopkinson bar four-point bend fracture test, is $\sim 58.7 \mathrm{MPa} \sqrt{\mathrm{m}}$ at a loading rate of $\sim 10^{6} \mathrm{MPa} \sqrt{\mathrm{m}} / \mathrm{s}$, which is higher than the quasistatic fracture toughness, $\sim 39.0 \mathrm{MPa} \sqrt{\mathrm{m}}$.

2. The fracture mechanism of Nitinol is strongly dependent upon the loading rate. With increasing loading rates, Nitinol exhibits an increasingly more ductile fracture response. The tendency for SIM transformation in the crack-tip region increases with increasing loading rate.

3. The SIM transformation plays an important role in the nucleation, growth, and coalescence of microvoids as well as in the crack-propagation behavior in the dynamic fracture of Nitinol, and is strongly linked to the increase in fracture toughness under dynamic loading, as compared to quasistatic loading.

\section{ACKNOWLEDGMENT}

The authors are very grateful to Professor Yongbo $\mathrm{Xu}$ for his insightful discussions on this article.

\section{REFERENCES}

1. S. Takaoka, H. Horikawa, J. Kobayashi, and K. Shimizu: Mater. Sci. Forum, 2002, vols. 394-395, pp. 61-68.

2. V. Birman: Appl. Mech. Rev., 1997, vol. 50, pp. 629-45.

3. J. Van Humbeeck: J. Alloys Compd., 2003, vol. 355, pp. 58-64.

4. D.E. Burkes, G. Gottoli, H.C. Yi, and J.J. Moore: Metall. Mater. Trans. A, 2001, vol. 32, pp. 731-43.

5. A. Shimamoto, T. Azakami, and T. Oguchi: Exp. Mech., 2003, vol. 43 , pp. $77-82$.

6. G. Murasawa, K. Tohgo, and H. Ishii: J. Compos. Mater., 2004, vol. 38, pp. 399-416.

7. W.D. Armstrong and T. Lorentzen: Metall. Mater. Trans. A, 2002, vol. 33A, pp. 3535-40.

8. G.A. Porter, P.K. Liaw, T.N. Tiegs, and K.H. Wu: Mater. Sci. Eng., A, 2001, vol. 314, pp. 186-93.

9. D.C. Lagoudas, K. Ravi-Chandar, K. Sarh, and P. Popov: Mech. Mater., 2003, vol. 35, pp. 689-716.

10. M. Kusagawa, T. Nakamura, and Y. Asada: JSME Int J., Ser. A, 2001, vol. 44, pp. 57-63.

11. J.A. Shaw and S. Kyriakides: J. Mech. Phys. Solids, 1995, vol. 43, pp. $1243-81$.

12. V.E. Panin, Y. Deryugin, L.S. Derevyagina, A.I. Lotkov, and B.I. Suvorov: Theor. Appl. Fract. Mech., 1998, vol. 30, pp. 19-26.

13. Y. Liu, Z. Xie, J. Van Humbeeck, and L. Delaey: Acta Mater., 1998, vol. 46, pp. 4325-38.

14. J.M. Mcnaney, V. Imbeni, Y. Jung, P. Papadopoulos, and R.O. Ritchie: Mech. Mater., 2003, vol. 35, pp. 969-86.

15. K. Gall, H. Sehitoglu, Y.I. Chumlyako, and I.V. Kireeva: Acta Mater., 1999, vol. 47, pp. 1203-17.

16. R. Plietsch and K. Ehrlich: Acta Mater., 1997, vol. 45, pp. 241724.

17. K. Jacobus, H. Sehitoglu, and M. Balzer: Metall. Mater. Trans. A, 1996, vol. 27A, pp. 3066-73.

18. D.A. Miller, W.R. Thissell, G.T. Gary III, and D.A.S. Macdougall: Adaptive Structures and Materials System, AD, ASME, New York, NY, 2000, vol. 60, pp. 51-58.

19. Y. Liu, Y. Li, K.T. Ramesh, and J. Van Humbeeck: Scripta Mater., 1999, vol. 41, pp. 89-95.

20. W.W. Chen, Qiuping Wu, Joseph H. Kang, and Nancy A. Winfree: Int. J. Solids Struct., 1002, vol. 38, pp. 8989-98.

21. S. Nemat-Nasser, J.Y. Choi, W.G. Gou, J. Isaacs, and M. Taya: J. Eng. Mater. Technol., Trans. ASME, 2005, vol. 127, pp. 83-89.

22. L. Wang, T. Kobayashi, Y. Harada, and K. Tsuchiya: Mater. Sci. Forum, 2005, vols. 475-479, pp. 4191-94.

23. R.R. Adharapurapu, F. Jiang, K.S. Vecchio, and G.T. Gray, III: Acta Mater., 2006, vol. 54, pp. 4609-20.

24. K. Gall, N. Yang, H. Sehitoglu, and Y. Chumlyakov: Int. J. Fract., 2001, vol. 109, pp. 189-207.

25. H. Tobushi, T. Nakahara, Y. Shimeno, and T. Hashimoto: Trans. ASME, 2000, vol. 122, pp. 186-91.

26. A.L. McKelvey and R.O. Ritchie: Metall. Mater. Trans. A, 2001, vol. 32A, pp. 731-43.

27. T. Sawaguchi, G. Kausträter, A. Yawny, M. Wagner, and G. Eggeler: Metall. Mater. Trans. A, 2003, vol. 34A, pp. 2847-60.

28. R. Vaidyanathan, D.C. Dunand, and U. Ramamurty: Mater. Sci. Eng., A, 2000, vol. 289, pp. 208-16.

29. E. Hornbogen: J. Mater. Sci., 2004, vol. 39, pp. 385-99.

30. H.F. López, A. Salinas, and H. Calderón: Metall. Mater. Trans. A, 2001, vol. 32A, pp. 717-29.

31. H.F. López: Mater. Lett., 2002, vol. 51, pp. 144-50.

32. X.M. Wang, Y.F. Wang, A. Baruj, G. Eggeler, and Z.F. Yue: Mater. Sci. Eng., A, 2005, vol. 394, pp. 393-98.

33. V. Birman: Smart Mater. Struct., 1998, vol. 7, pp. 433-37.

34. G.Z. Wang: Mater. Sci. Eng., A, 2006, vol. 434, pp. 269-79.

35. G.Z. Wang: Mater. Sci. Eng., A, 2007, vols. 460-461, pp. 383-91.

36. X. Wang and Z. Yue: Key Eng. Mater., 2006, vols. 324-325, pp. 919-22.

37. S. Yi and S. Gao: Int. J. Solids Struct., 2000, vol. 37, pp. 5313-27.

38. S. Yi, S. Gao, and L. Shen: Int. J. Solids Struct., 2001, vol. 38, pp. $4463-76$.

39. W. Yan, C.U. Wang, X.P. Zhang, and Y.-W. Mai: Smart Mater. Struct., 2002, vol. 11, pp. 947-55.

40. J.H. Chen, W. Sun, and G.Z. Wang: Metall. Mater. Trans. A, 2005, vol. 36A, pp. 941-55. 
41. J.Y. He, K.W. Gao, Y.J. Su, L.J. Qiao, and W.Y. Chu: Smart Mater. Struct., 2004, vol. 13, pp. N24-N28.

42. S.W. Robertson and R.O. Ritchie: Biomater., 2007, vol. 28, pp. 700-09.

43. F. Jiang, K.S. Vecchio, and A. Rohatgi: Int. J. Fract., 2004, vol. 126, pp. 143-64

44. F. Jiang, K.S. Vecchio: Metall. Mater. Trans. A, 2007, vol. 38A, in press.

45. Y. Murakami: Stress Intensity Factor Handbook, vol. 1, Pergamon Press, Oxford, United Kingdom, 1987, p. 687.

46. J. Zhang and J. Lewandowski: J. Mater. Sci., 1997, vol. 32, pp. 3851-56.

47. S.-X. Wu, Y.-W. Mai, B. Cotterell, and C.V. Le: Acta Metall. Mater., 1991, vol. 39, pp. 2527-32.

48. M. Coates, A. Kumar, and S.G. Roberts: Fatigue Fract. Eng. Mater. Struct., 2006, vol. 29, pp. 661-71.

49. H.-J. Sue: Polym. Eng. Sci., 1991, vol. 31, pp. 270-74.

50. J. Wu and Y.-W. Mai: J. Mater. Sci., 1993, vol. 28, pp. 6167-77.

51. R.K. Nalla, J.H. Kiney, and R.O. Ritchie: Nat. Mater., 2003, vol. 2, pp. 164-68.
52. Y.-R. Im, B.-J. Lee, Y.J. Oh, J.H. Hong, and H.-C. Lee: J. Nucl. Mater., 2004, vol. 32, pp. 33-40.

53. J.J. Lewandowski and A.W. Thompson: Metall. Trans. A, 1986, vol. 17A, pp. 461-72.

54. J.J. Lewandowski, C.A. Hippsley, M.B.D. Ellis, and J.F. Knott: Acta Metall., 1987, vol. 35, pp. 593-609.

55. C.A. Hippsley and J.J. Lewandowski: Metall. Trans. A, 1988, vol. 19 , pp. $3005-11$

56. J.J. Lewandowski, C. Liu, and W.H. Hunt, Jr.: Mater. Sci. Eng. A, 1989, vol. 107, pp. 241-55.

57. P.S. Khadkikar, J.J. Lewandowski, and K. Vedula: Metall. Trans. A, 1989, vol. 20, pp. 1247-55.

58. P.R. Guduru, A.T. Zehnde, A.J. Rosakis, and G. Ravichandran: Eng. Fract. Mech., 2001, vol. 68, pp. 1535-56.

59. J.J. Lewandowski and A.L. Greer: Nat. Mater., 2006, vol. 5, pp. $15-18$.

60. T.L. Panontin and S.D. Sheppard: ASTM STP 1296, ASTM, Philadelphia, PA, 1997, pp. 216-42. 